\title{
Asymptomatic Malaria Correlates with Anaemia in Pregnant Women at Ouagadougou, Burkina Faso
}

\author{
Zoenabo Douamba, ${ }^{1,2}$ Cyrille Bisseye, ${ }^{1,3}$ Florencia W. Djigma, ${ }^{1,2}$ \\ Tegwinde R. Compaoré, ${ }^{1}$ Valérie Jean Telesphore Bazie, ${ }^{1}$ Virginio Pietra, ${ }^{1,2}$ \\ Jean-Baptiste Nikiema, ${ }^{1,2}$ and Jacques Simpore ${ }^{1,2}$ \\ ${ }^{1}$ Biomolecular Research Center Pietro Annigoni (CERBA), Labiogene, UFR/SVT, University of Ouagadougou, \\ 01 BP 364, Ouagadougou 01, Burkina Faso \\ ${ }^{2}$ Saint Camille Medical Centre, Ouagadougou, Burkina Faso \\ ${ }^{3}$ Department of Biology, University of Sciences and Techniques of Masuku (USTM), Franceville, Gabon
}

Correspondence should be addressed to Cyrille Bisseye, cbisseye@gmail.com

Received 21 September 2012; Revised 14 October 2012; Accepted 15 October 2012

Academic Editor: Kazim Husain

Copyright (C) 2012 Zoenabo Douamba et al. This is an open access article distributed under the Creative Commons Attribution License, which permits unrestricted use, distribution, and reproduction in any medium, provided the original work is properly cited.

Sub-Saharan Africa records each year about thirty-two million pregnant women living in areas of high transmission of Plasmodium falciparum causing malaria. The aim of this study was to carve out the prevalence of asymptomatic malaria among pregnant women and to emphasize its influence on haematological markers. The prevalence of Plasmodium falciparum asymptomatic infection among pregnant women was $30 \%$ and $24 \%$ with rapid detection test (RDT) and microscopy, respectively. The prevalence of $P$. falciparum asymptomatic malaria was reduced among pregnant women using sulfadoxine-pyrimethamine's intermittent preventive treatment and $61 \%$ of them were anaemic. Anaemia was significantly more common in women infected with $P$. falciparum compared with the uninfected pregnant women. Most of the women had normal levels of homocysteine and low levels of folate, respectively. Therefore, the systematic diagnosis of malaria should be introduced to pregnant women as a part of the antenatal care.

\section{Introduction}

Sub-Saharan Africa records each year about thirty-two million pregnant women living in areas of high transmission of Plasmodium falciparum causing malaria [1]. In malaria-endemic areas, malaria is the cause for almost $25 \%$ of maternal deaths each year [2], with the greatest risk of infection and morbidity occurring in primiparous women, adolescents, and those coinfected with HIV.

Malaria is still the leading cause of medical consultation in Burkina Faso. In 2009, malaria accounted for 45\% of medical consultation, $57 \%$ of hospitalization, and $51 \%$ of mortality. The number of clinical cases of malaria recorded in health care facilities was 4,507,420 including 11,810 deaths. Malaria's morbidity affected 15,394 pregnant women with 172 deaths among them [3].

A previous study demonstrated that asymptomatic malaria in pregnant women induces maternal anaemia and low birth weight infants [4]. In areas of malaria transmission such as Burkina Faso, infection with P. falciparum in pregnant women may be asymptomatic but accompanied by secondary anaemia and a placental parasitaemia.

In Burkina Faso, many studies have investigated the course of acute malaria during pregnancy [5-7], but there are only few data on asymptomatic malaria in pregnant women.

The purpose of this study was to evaluate the prevalence of asymptomatic malaria among pregnant women. Our study also assessed the relationship between pregnant women's biochemical and haematological parameters and asymptomatic malaria.

\section{Materials and Methods}

2.1. Population. The study was conducted at Saint Camille Medical Centre (CMSC) in Ouagadougou during the malaria transmission season from September until October 2010. 
Two hundred and one (201) primigravida and multigravida without any prior evidence of clinical malaria were recruited into the study. After obtaining consent, up to $5 \mathrm{~mL}$ of their venous blood was collected. Asymptomatic malaria infection was assessed by rapid detection test Acon (ACON Malaria Pf, San Diego, USA) and microscopic examination of Giemsa-stained thick and thin blood smears. All slides were read twice by experienced microscopists and discrepancies resolved by a third reader (limit of detection, approximately 2 parasites/mL) [8]. The study was approved by the Joint CERBA/Saint Camille Ethics Committee.

2.2. Haematological and Biochemical Parameters of Pregnant Women. $\mathrm{ABO}$ and $\mathrm{Rh}$ blood groups determinations were carried out on a slide using monoclonal blood grouping antisera; anti-A, anti-B, anti-AB, and anti-D (BIOTEC Laboratories Ltd., Great Britain).

Haemoglobin and serum iron levels were performed using two colorimetric kits (Cypress DIAGNOSTICS, Langdorp, Belgium) following the manufacturer's instructions. Haemoglobin typing was performed by cellulose acetate electrophoresis.

Dosages of folate and homocysteine were made using AxSYM kits for folate and homocysteine (Abbott, Santa Clara, CA, USA) following the manufacturer's instructions.

2.3. Statistical Analysis. Data were entered and analyzed using SPSS version 17 statistical package and EPI-Info version $6.04 \mathrm{dfr}$ (CDC, Atlanta, USA). Differences in the prevalence of asymptomatic malaria for sociodemographic, haematological, and biochemistry variables were tested for significance using chi square tests. $P$ value less than 0.05 was considered statistically significant.

\section{Results}

3.1. Sociodemographic Characteristics of Pregnant Women. Two hundred and one women (201) agreed to participate in the study. Pregnant women were aged from 18 to 39 years with a mean age of $25 \pm 5$ years. Most of the pregnant women belonged to an age group under 30 years (78\%). Women were from different professional groups; the majority was housewives (61\%), illiterate (42\%), and multiparous $(65 \%)$. Only $42 \%$ of all pregnant women were using an insecticidetreated net (ITN) and 40\% were taking an iron supplement as shown in Table 1.

3.2. Prevalence of Plasmodium falciparum Asymptomatic Malaria in Pregnant Women. The prevalence of Plasmodium falciparum asymptomatic infection among pregnant women was $30 \%$ and $24 \%$ with rapid detection test (RDT) and microscopy, respectively.

The Acon rapid test had a sensitivity of $100 \%$ and a specificity of $92 \%$ for the detection of Plasmodium falciparum asymptomatic malaria compared to microscopic diagnosis. The mean parasite density observed in pregnant women was 4058 parasites $/ \mu \mathrm{L}$.
TABLE 1: Sociodemographic characteristics of pregnant women.

\begin{tabular}{|c|c|c|}
\hline Characteristics & Number & Percentage (\%) \\
\hline \multicolumn{3}{|l|}{ Profession } \\
\hline Housewife & 123 & 61 \\
\hline Informal sector & 60 & 30 \\
\hline Employee & 5 & 2 \\
\hline Student & 13 & 7 \\
\hline \multicolumn{3}{|l|}{ Education level } \\
\hline Illiterate & 84 & 42 \\
\hline Primary & 59 & 29 \\
\hline Postprimary & 58 & 29 \\
\hline \multicolumn{3}{|l|}{ Age (years) } \\
\hline$\leq 20$ & 50 & 25 \\
\hline $21-25$ & 59 & 29 \\
\hline $26-30$ & 59 & 29 \\
\hline $31-39$ & 33 & 16 \\
\hline \multicolumn{3}{|l|}{ Number of children } \\
\hline 1 & 70 & 35 \\
\hline 2 & 45 & 22 \\
\hline$\geq 3$ & 86 & 43 \\
\hline \multicolumn{3}{|l|}{ Stage of pregnancy } \\
\hline 1st trimestre & 70 & 35 \\
\hline 2nd trimestre & 96 & 48 \\
\hline 3rd trimestre & 35 & 17 \\
\hline \multicolumn{3}{|c|}{ Use of impregnated bednet } \\
\hline Yes & 85 & 42 \\
\hline No & 116 & 58 \\
\hline \multicolumn{3}{|c|}{ Use of iron and folic acid } \\
\hline Yes & 81 & 40 \\
\hline No & 120 & 60 \\
\hline
\end{tabular}

3.3. Haematological and Biochemical Parameters in Pregnant Women. As shown in Table 2, the average of haemoglobin level in pregnant women was $10.5 \pm 1.7 \mathrm{~g} / \mathrm{dL}$. The majority of pregnant women $(61 \%)$ had a haemoglobin level of $<11 \mathrm{~g} / \mathrm{dL}$ and a normal level of serum iron (83\%). Homocysteine and folate levels were also measured in pregnant women. Most of the women $(90 \%$ and $62 \%$ ) had normal levels of homocysteine $(\leq 12 \mathrm{mmol} / \mathrm{L})$ and low levels of folate $(<7.7 \mathrm{ng} / \mathrm{mL})$, respectively.

We found that anaemia was significantly more common in women infected with $P$. falciparum (33\%) compared with the uninfected pregnant women $(10 \%)(P=0.0002)$ (Table 3).

We did not observe statistically significant differences between both gravida and asymptomatic malaria and the use of insecticide-treated nets and $P$. falciparum asymptomatic malaria. However, the presence of $P$. falciparum was significantly reduced in pregnant women who had received intermittent preventive treatment based on sulfadoxinepyrimethamine (SP) (13\%) compared to those without treatment (29\%) $(P=0.0182)$ (Table 3$)$. Among the pregnant women, the prevalence of HbAS (8\%), HbAC (16\%), HbCC (1\%), 
TABLE 2: Hematological and biochemistry parameters of pregnant women.

\begin{tabular}{|c|c|c|c|c|}
\hline Parameters & & $\begin{array}{c}\text { Normal } \\
\text { values }\end{array}$ & Number & Percentage \\
\hline \multirow{4}{*}{$\begin{array}{l}\text { Haemoglobin level } \\
(10.49 \pm 1.73 \mathrm{~g} / \mathrm{dL})\end{array}$} & Severe anaemia & $<7$ & 2 & 1 \\
\hline & Moderate anaemia & {$[7-10[$} & 74 & 37 \\
\hline & Slight anaemia & {$[10-11[$} & 47 & 23 \\
\hline & Absence of anaemia & $\geq 11$ & 78 & 39 \\
\hline \multirow{3}{*}{$\begin{array}{l}\text { Serum iron } \\
(14.64 \pm 1.96 \mu \mathrm{mol} / \mathrm{L})\end{array}$} & Low & $<7.16$ & 21 & 10 \\
\hline & Normal & $7.16-26.85$ & 167 & 83 \\
\hline & High & $>26.85$ & 13 & 7 \\
\hline \multirow{2}{*}{$\begin{array}{l}\text { Folate } \\
(7.01 \pm 2.84 \mathrm{ng} / \mathrm{mL})\end{array}$} & Low & $<7.7$ & 125 & 62 \\
\hline & Normal & $\geq 7.7$ & 76 & 38 \\
\hline \multirow{3}{*}{$\begin{array}{l}\text { Homocysteine } \\
(10.49 \pm 1.73 \mu \mathrm{mol} / \mathrm{L})\end{array}$} & Normal & $\leq 12$ & 181 & 90 \\
\hline & Moderate Homocysteinaemia & ]12-30[ & 18 & 9 \\
\hline & Hyperhomocysteinaemia & $\geq 30$ & 2 & 1 \\
\hline
\end{tabular}

TABLE 3: Prevalence of $P$. falciparum in pregnant women according to their hematological and sociodemographic status.

\begin{tabular}{|c|c|c|c|c|}
\hline \multirow{2}{*}{ Parameters } & & \multicolumn{2}{|c|}{ Blood smears } & \multirow[t]{2}{*}{$P$ value } \\
\hline & & Negative & Positive & \\
\hline \multirow{3}{*}{ Haemoglobin level } & Presence of anaemia & $82 / 123(67 \%)$ & $41 / 123(33 \%)$ & \multirow{3}{*}{0.0002} \\
\hline & $N=123 / 201(61 \%)$ & & & \\
\hline & $\begin{array}{c}\text { Absence of anaemia } \\
N=78 / 201(39 \%)\end{array}$ & $70 / 78(90 \%)$ & $8 / 78(10 \%)$ & \\
\hline \multirow{3}{*}{ Stage of pregnancy } & $\begin{array}{c}\text { 1st trimestre } \\
N=70 / 201(35 \%)\end{array}$ & $55 / 70(79 \%)$ & $15 / 70(23 \%)$ & \multirow{3}{*}{ NS } \\
\hline & $\begin{array}{c}\text { 2nd trimestre } \\
N=96 / 201(48 \%)\end{array}$ & $68 / 96(71 \%)$ & $28 / 96(29 \%)$ & \\
\hline & $\begin{array}{c}\text { 3rd trimestre } \\
N=35 / 201(17 \%)\end{array}$ & $29 / 35(83 \%)$ & $6 / 35(17 \%)$ & \\
\hline \multirow{3}{*}{ Number of pregnancy } & $\begin{array}{c}1 \\
N=70 / 201(35 \%)\end{array}$ & $53 / 70(76 \%)$ & $17 / 70(24 \%)$ & \multirow{3}{*}{ NS } \\
\hline & $\begin{array}{c}2 \\
N=45 / 201(22 \%)\end{array}$ & $34 / 45(76 \%)$ & $11 / 45(24 \%)$ & \\
\hline & $\begin{array}{c}\geq 3 \\
N=86 / 201(43 \%)\end{array}$ & $65 / 86(76 \%)$ & $21 / 86(24 \%)$ & \\
\hline \multirow{2}{*}{$\begin{array}{l}\text { Preventive treatment } \\
\text { (SP) }\end{array}$} & $\begin{array}{c}\text { Yes } \\
N=146 / 201(73 \%)\end{array}$ & $104 / 146(71 \%)$ & $42 / 146(29 \%)$ & \multirow{2}{*}{0.0182} \\
\hline & $\begin{array}{c}\text { No } \\
N=55 / 201(27 \%)\end{array}$ & $48 / 55(87 \%)$ & $7 / 55(13 \%)$ & \\
\hline \multirow{5}{*}{ Haemoglobin type } & $\mathrm{AA}(74 \%)$ & $74 \%$ & $26 \%$ & \multirow{5}{*}{ NS } \\
\hline & $\mathrm{AC}(16 \%)$ & $81 \%$ & $19 \%$ & \\
\hline & AS $(8 \%)$ & $75 \%$ & $25 \%$ & \\
\hline & CC $(1 \%)$ & $1 / 1$ & $0 / 1$ & \\
\hline & SC $(1 \%)$ & $2 / 2$ & $0 / 2$ & \\
\hline \multirow{4}{*}{ Blood groups } & $\mathrm{A}(25 \%)$ & $72 \%$ & $28 \%$ & \multirow{4}{*}{ NS } \\
\hline & B $(31 \%)$ & $73 \%$ & $27 \%$ & \\
\hline & $\mathrm{AB}(9 \%)$ & $71 \%$ & $29 \%$ & \\
\hline & $\mathrm{O}(35 \%)$ & $82 \%$ & $18 \%$ & \\
\hline
\end{tabular}

NS: not significant; in bold: significant $P$ values. 
and HbSC (1\%) hemoglobin types was not associated with asymptomatic malaria (Table 3 ).

We found that pregnant women from blood group $\mathrm{O}$ were less infected by $P$. falciparum than those belonging to the non-O blood groups but the difference was not statistically significant.

\section{Discussion}

This work aimed to study asymptomatic malaria among pregnant women consulting Saint Camille Medical Centre at Ouagadougou in Burkina Faso. We have shown that the prevalence of asymptomatic malaria among women was 30\% and $24 \%$ using an RDT and microscopy, respectively. The difference was not significant but could be explained by the persistence of histidine rich protein 2 (HRP-2) antigen of $P$. falciparum after the parasite clearance [9]. The RDT used had a sensitivity of $100 \%$ and a specificity of $92 \%$ compared to conventional microscopy. Our results are comparable to those from studies in Cote d'Ivoire and Senegal with sensitivities of $100 \%$ and $96 \%$ and specificities of $88 \%$ and $87 \%$, respectively, $[10,11]$.

We evaluated through a questionnaire the use of ITNs in pregnant women. Only $42 \%$ of the women used an ITN. Several reasons explain the low use of ITNs: psychological effects of suffocation, ignorance of the risks of malaria during pregnancy, and the cost of the net. Utilization of ITNs varies between studies, $58 \%$ and $9 \%$ in Burkina $[6,12]$ and $16 \%$ in Nigeria [13].

The fight against malaria in pregnant women involves the use of insecticide-treated nets and intermittent preventive treatment (IPT) with sulfadoxine-pyrimethamine (SP). Thus, all pregnant women living in areas of stable malaria transmission should receive at least two doses of IPT as recommended by the World Health Organization [14].

Only $27 \%$ of the pregnant women have taken the first dose of SP and less than half of the women used iron supplement and folic acid. This low use of iron and SP can be explained by the fact that most of the women began their prenatal checks from the fifth month of the pregnancy for various reasons including the ignorance of risk associated with poorly managed and monitored pregnancy and a lack of financial resources.

The use of SP as an intermittent preventive treatment by pregnant women was associated with a reduced prevalence of $P$. falciparum asymptomatic infection compared to those who did not receive SP (13\% versus $29 \%, P=0.0182)$. Our results are comparable to those obtained in Ghana [15] where $15 \%$ versus $45 \%$ of $P$. falciparum infection was observed among pregnant women in the presence or absence of the intermittent preventive treatment, respectively.

WHO defined anaemia in pregnant women as a haemoglobin level <11 g/dL [16]. We found that 61\% (123/ 201) of the pregnant women in the study were anaemic. Interestingly, this anaemia was correlated with the presence of $P$. falciparum asymptomatic. Indeed, 33\% of all pregnant anaemic women were positive for $P$. falciparum compared with $10 \%$ of anaemic women without parasitaemia. The prevalence of anaemia observed in this study is comparable to those of previous studies obtained 66\% [17], 64\% [12] in Burkina Faso, and 64\% [18] in Benin. The correlation between $P$. falciparum and anemia found in this study is similar to those reported in Nigeria $[19,20]$.

We did not find a significant correlation between anaemia and gravida. This is in accordance with a previous report on $P$. falciparum asymptomatic malaria in Nigerian pregnant women [21]. However, other studies have shown higher rates of anaemic women in primiparous women compared to multiparous ones $[19,22,23]$.

Nutrical deficiencies including iron and folic acid have been linked to anaemia. Our study shows that $83 \%$ of pregnant women had a normal serum iron but $62 \%$ of them had a low level of folate; this is in discordance with what has been previously reported on Nigerian pregnant women [24].

High levels of homocysteine (HCY) play a role in pregnancy complications such as an increased risk of eclampsia, spina bifida malformation, children with low birth weight, stillbirths, and premature births [25]. Most pregnant women (90\%) had normal values of homocysteine $(\leq 12 \mu \mathrm{mol} / \mathrm{L})$. The mean value of homocysteine $(10.5 \mu \mathrm{mol} / \mathrm{L})$ found in pregnant women is higher than the value of $3.6 \mu \mathrm{mol} / \mathrm{L}$ obtained in healthy women in Burkina Faso [26]. This difference could be explained by physiological changes during pregnancy. However, the average homocysteine levels found in our study were lower than those found in Nigeria $(14.1 \mu \mathrm{mol} / \mathrm{L})[24]$ and the difference could be due to the high prevalence of moderate hyperhomocysteinaemia among adolescents and adults of both sexes in the Nigerian population [27]. Indeed studies conducted in Burkina showed that plasma homocysteine (HCY) varies according to gender, age, and nutritional habits $[26,28]$. We did not find an association between haemoglobin type and anaemia in pregnant women. With regard to blood groups, we found that pregnant women of blood group $\mathrm{O}$ were less infected than those of non-O blood groups, but this difference was not significant. However, that study in Nigeria found that pregnant women group $\mathrm{O}$ were more infected by $P$. falciparum [4].

Our findings are interesting because we have demonstrated as previously reported in other studies $[4,29]$ that $P$. falciparum asymptomatic malaria is responsible for anaemia in pregnant women in Burkina Faso. However, there are some potential limitations in our study to be considered. First, P. falciparum asymptomatic malaria was identified using RDT and optical microscopy. The sensitivity of these tests is low for the detection of very low parasitaemia. Indeed, a recent study has shown a higher prevalence of asymptomatic malaria detected by polymerase chain reaction (PCR) compared with other diagnostic methods [9]. Thus, the prevalence of asymptomatic malaria reported in our study may be underestimated. In addition, to define anaemia we only measured haemoglobin levels among pregnant women.

Several studies documented an impact of asymptomatic malaria on haematological markers like blood count, ferritin, and transferrin levels [30-32]. But our study did not include the evaluation of those parameters.

A subsequent study could focus on the role of folic acid in reducing anaemia among pregnant women with mild or 
asymptomatic malaria. Intermittent preventive treatment of malaria in pregnant women is ensured by SP. Therefore, monitoring of SP resistance by $P$. falciparum is necessary among pregnant women.

\section{Conclusion}

This study revealed a high prevalence of asymptomatic malaria among pregnant women in Burkina Faso. This asymptomatic infection is responsible for anaemia in pregnant women and may count in mother to children malaria transmission. Therefore, the systematic diagnosis of malaria should be introduced to pregnant women as a part of the antenatal care. In addition, intermittent preventive treatment of malaria and the use of ITNs should be strengthened among pregnant women in Burkina Faso.

\section{Acknowledgments}

The authors are grateful to the staff of Saint Camille laboratory and CERBA, Ouagadougou. They are deeply grateful to the Italian Episcopal Conference (C. E. I), to UEMOA, and to the RADIM House, Roma, Italy. They would like to thank Dr. Med Guzin Surat for reading critically the paper.

\section{References}

[1] S. Dellicour, A. J. Tatem, C. A. Guerra, R. W. Snow, and F. O. Ter Kuile, "Quantifying the number of pregnancies at risk of malaria in 2007: a demographic study," PLoS Medicine, vol. 7, no. 1, Article ID e1000221, 2010.

[2] J. Schantz-Dunn and N. M. Nour, "Malaria and pregnancy: a global health perspective," Review in Obstetrics and Gynecology, vol. 2, no. 3, pp. 186-192, 2009.

[3] Ministère de la santé/ direction générale de l'information et des statistiques du Burkina Faso, "Annuaire statistique 2009," http://www.cns.bf/IMG/pdf/Synthese_Annuaire.pdf.

[4] C. J. Uneke, I. Sunday-Adeoye, F. E. Iyare, E. I. Ugwuja, and D. D. Duhlinska, "Impact of maternal Plasmodium falciparum malaria and haematological parameters on pregnancy and its outcome in southeastern Nigeria," Journal of Vector Borne Diseases, vol. 44, no. 4, pp. 285-290, 2007.

[5] C. Miaffo, F. Some, B. Kouyate, A. Jahn, and O. Mueller, "Malaria and anemia prevention in pregnant women of rural Burkina Faso," BMC Pregnancy and Childbirth, vol. 4, no. 1, pp. 18-24, 2004.

[6] S. O. Coulibaly, S. Gies, and U. D’Alessandro, "Malaria burden among pregnant women living in the rural district of Boromo, Burkina Faso," The American Journal of Tropical Medicine and Hygiene, vol. 77, no. 6, pp. 56-60, 2007.

[7] I. Valea, H. Tinto, M. K. Drabo et al., "An analysis of timing and frequency of malaria infection during pregnancy in relation to the risk of low birth weight, anaemia and perinatal mortality in Burkina Faso," Malaria Journal, vol. 11, no. 1, pp. 71-77, 2012.

[8] A. Moody, "Rapid diagnostic tests for malaria parasites," Clinical Microbiology Reviews, vol. 15, no. 1, pp. 66-78, 2002.

[9] J. H. Kattenberg, C. M. Tahita, I. A. J. Versteeg et al., "Antigen persistence of rapid diagnostic tests in pregnant women in Nanoro, Burkina Faso and the implications for the diagnosis of malaria in pregnancy," Tropical Medicine and International Health, vol. 17, no. 2, pp. 550-557, 2012.

[10] W. Yavo, K. N. Ackra, E. I. H. Menan et al., "Comparative study of four techniques used in Côte d'Ivoire for malaria's biological diagnosis," Bulletin de la Societe de Pathologie Exotique, vol. 95 , no. 4, pp. 238-240, 2002.

[11] A. Munier, A. Diallo, C. Sokhna, and J. P. Chippaux, "Assessment of a rapid diagnostic test for malaria in rural health care facilities in Senegal," Médecine Tropicale, vol. 69, no. 5, pp. 496-500, 2009.

[12] S. B. Sirima, A. H. Cotte, A. Konaté et al., "Malaria prevention during pregnancy: assessing the disease burden one year after implementing a program of intermittent preventive treatment in Koupéla District, Burkina Faso," American Journal of Tropical Medicine and Hygiene, vol. 75, no. 2, pp. 205-211, 2006.

[13] M. Efunshile, A. O. J. Amoo, G. B. Akintunde, O. D. Ojelekan, W. König, and B. König, "Use and effects of malaria control measures in pregnancy in Lagos," Korean Journal of Parasitology, vol. 49, no. 4, pp. 365-371, 2011.

[14] OMS, Cadre stratégique pour la prévention et la lutte contre le paludisme pendant la grossesse dans la région africaine, Organisation Mondiale de la Santé, Brazzaville, Congo, 2005.

[15] N. O. Wilson, F. K. Ceesay, S. A. Obed et al., "Intermittent preventive treatment with sulfadoxine-pyrimethamine against malaria and anemia in pregnant women," American Journal of Tropical Medicine and Hygiene, vol. 85, no. 1, pp. 12-21, 2011.

[16] WHO, Iron Deficiency Anaemia Assessment, Prevention and Control: A Guide For Programme Managers, World Health Organization, Geneva, Switzerland, 2001.

[17] N. Meda, L. Mandelbrot, M. Cartoux, B. Dao, A. Ouangré, and F. Dabis, "Anaemia during pregnancy in Burkina Faso, West Africa, 1995-96: Prevalence and associated factors," Bulletin of the World Health Organization, vol. 77, no. 11, pp. 916-922, 1999.

[18] F. Bodeau-Livinec, V. Briand, J. Berger et al., "Maternal anemia in Benin: prevalence, risk factors, and association with low birth weight," American Journal of Tropical Medicine and Hygiene, vol. 85, no. 3, pp. 414-420, 2011.

[19] O. Erhabor, T. C. Adias, and M. L. Hart, "Effects of falciparum malaria on the indices of anaemia among pregnant women in the Niger Delta of Nigeria," Journal of Clinical Medicine and Research, vol. 2, no. 3, pp. 035-041, 2010.

[20] G. T. A. Jombo, E. M. Mbaawuaga, A. S. Ayegba, and M. A. Araoye, "Anaemia, malaria burden and its control methods among pregnant women in a semi-urban community of northern Nigeria," Journal of Public Health and Epidemiology, vol. 3, no. 7, pp. 317-323, 2011.

[21] T. U. Agan, J. E. Ekabua, A. E. Udoh, E. I. Ekanem, E. E. Efiok, and M. A. Mgbekem, "Prevalence of anemia in women with asymptomatic malaria parasitemia at first antenatal care visit at the University of Calabar Teaching Hospital, Calabar, Nigeria," International Journal of Women's Health, vol. 2, no. 1, pp. 229-233, 2010.

[22] M. Glover-Amengor and W. B. Owusuand B. D. Akanmori, "Determinants of anaemia in pregnancy in Sekyere West District, Ghana," Ghana Medical Journal, vol. 39, no. 3, pp. 102-107, 2005.

[23] M. F. Ofori, E. Ansah, I. Agyepong, D. Ofori-Adjei, L. Hviid, and B. D. Akanmori, "Pregnancy-associated malaria in a rural community of Ghana," Ghana Medical Journal, vol. 43, no. 10, pp. 13-18, 2009.

[24] D. J. VanderJagt, H. S. Brock, G. S. Melah, A. U. El-Nafaty, M. J. Crossey, and R. H. Glew, "Nutritional factors associated with anaemia in pregnant women in northern Nigeria," Journal of 
Health, Population and Nutrition, vol. 25, no. 1, pp. 75-81, 2007.

[25] S. E. Vollset, H. Refsum, L. M. Irgens et al., "Plasma total homocysteine, pregnancy complications, and adverse pregnancy outcomes: the Hordaland Homocysteine Study," American Journal of Clinical Nutrition, vol. 71, no. 4, pp. 962-968, 2000.

[26] J. Simporè, S. Pignatelli, S. Barlati, M. Malaguarnera, and S. Musumeci, "Plasma homocysteine concentrations in a healthy population living in burkina faso," Current Therapeutic Research, vol. 61, no. 9, pp. 659-668, 2000.

[27] D. J. VanderJagt, K. Spelman, J. Ambe et al., "Folate and Vitamin B12 status of adolescent girls in Northern Nigeria," Journal of the National Medical Association, vol. 92, no. 7, pp. 334-340, 2000.

[28] R. Chillemi, J. Simpore, S. Persichilli, A. Minucci, A. D’Agata, and S. Musumeci, "Elevated levels of plasma homocysteine in postmenopausal women in Burkina Faso," Clinical Chemistry and Laboratory Medicine, vol. 43, no. 7, pp. 765-771, 2005.

[29] L. Muhangi, P. Woodburn, M. Omara et al., "Associations between mild-to-moderate anaemia in pregnancy and helminth, malaria and HIV infection in Entebbe, Uganda," Transactions of the Royal Society of Tropical Medicine and Hygiene, vol. 101, no. 9, pp. 899-907, 2007.

[30] C. Igbeneghu, A. B. Odaibo, and D. O. Olaleye, "Impact of asymptomatic malaria on some hematological parameters in the iwo community in southwestern nigeria," Medical Principles and Practice, vol. 20, no. 5, pp. 459-463, 2011.

[31] N. N. Odunukwe, L. A. Salako, C. Okany, and M. M. Ibrahim, "Serum ferritin and other haematological measurements in apparently healthy adults with malaria parasitaemia in Lagos, Nigeria," Tropical Medicine and International Health, vol. 5, no. 8 , pp. 582-586, 2000.

[32] F. P. Mockenhaupt, J. May, K. Stark, A. G. Falusi, C. G. Meyer, and U. Bienzle, "Serum transferrin receptor levels are increased in asymptomatic and mild Plasmodium falciparuminfection," Haematologica, vol. 84, no. 10, pp. 869-873, 1999. 


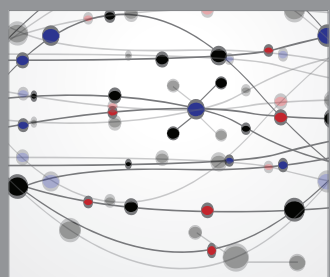

The Scientific World Journal
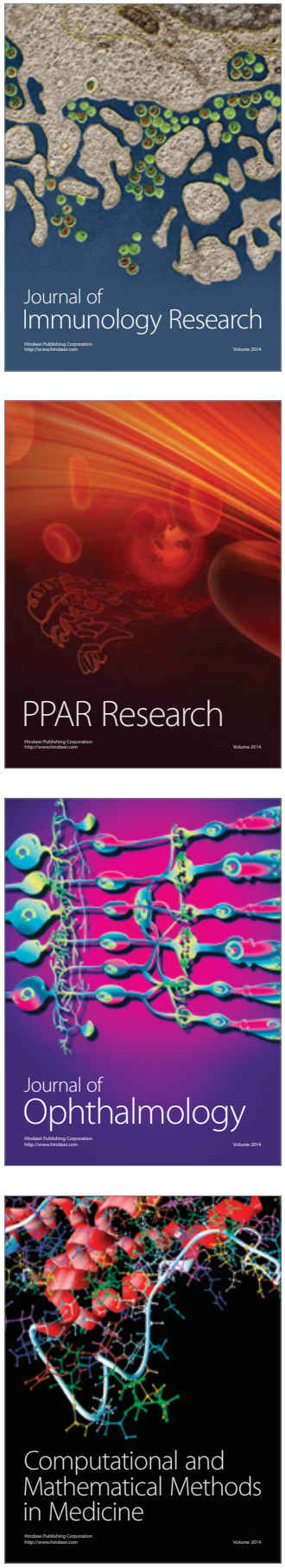

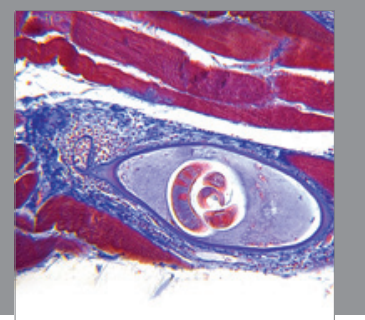

Gastroenterology

Research and Practice
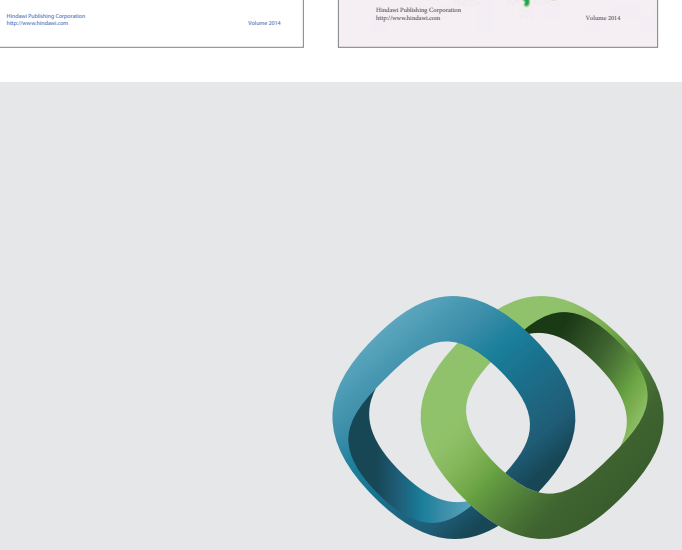

\section{Hindawi}

Submit your manuscripts at

http://www.hindawi.com
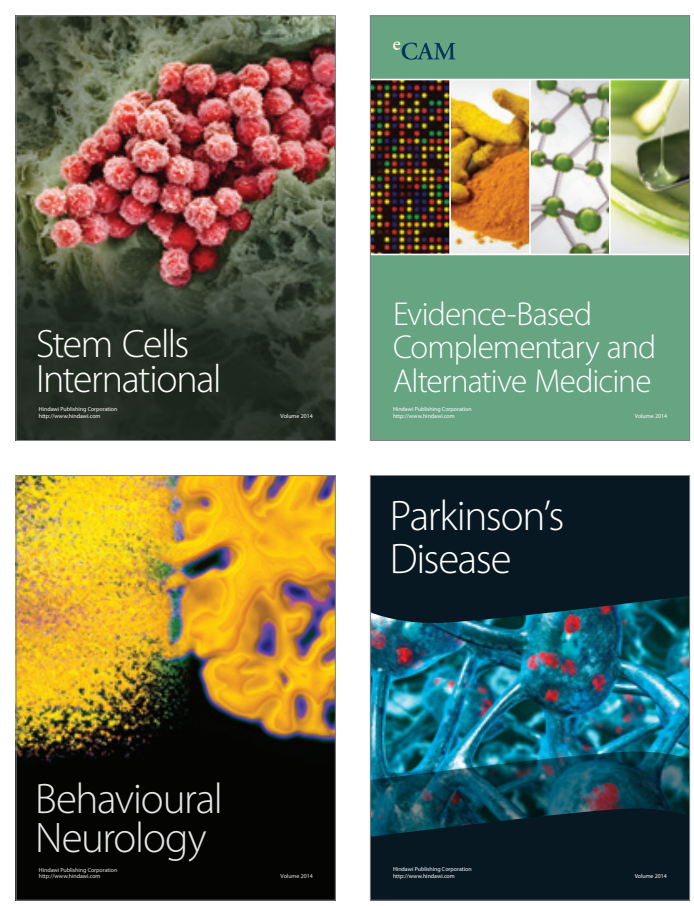

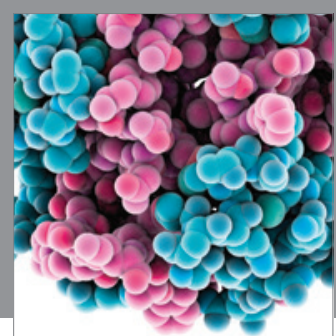

Journal of
Diabetes Research

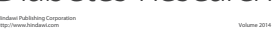

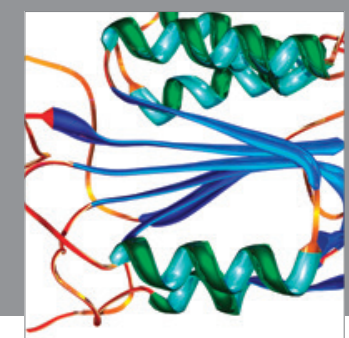

Disease Markers
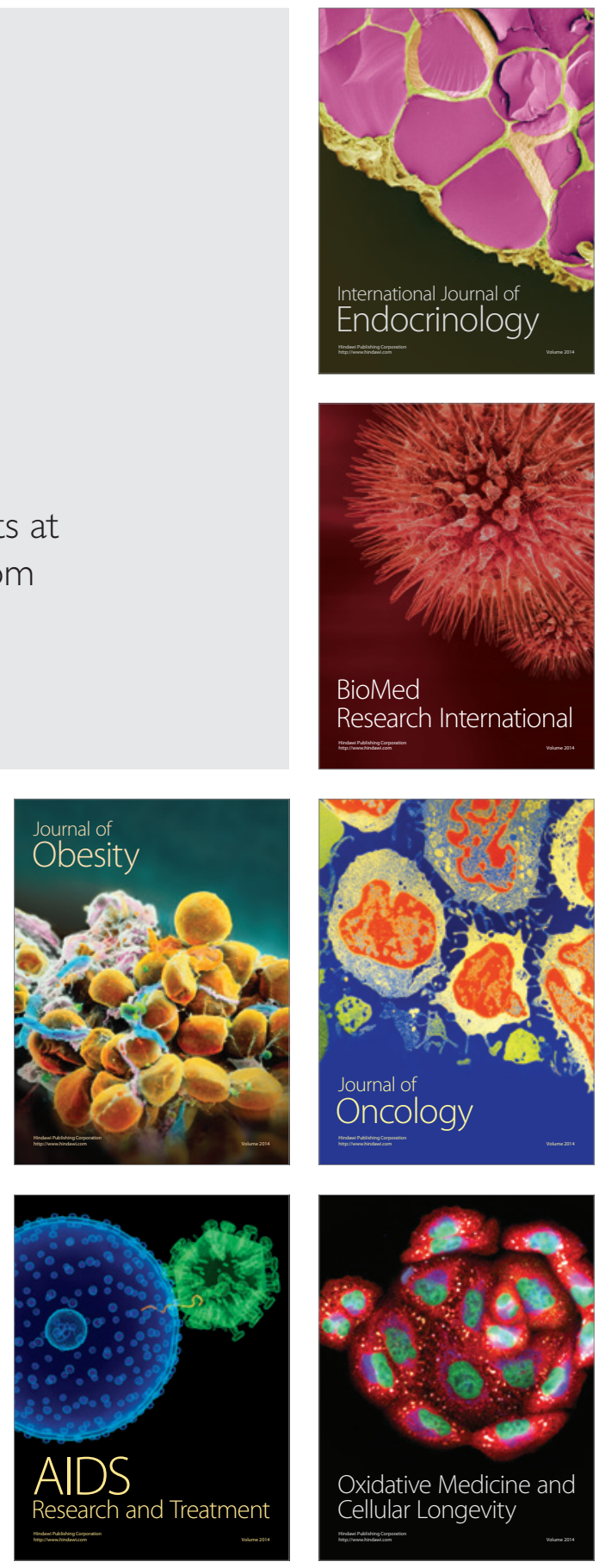